\title{
LEARNING ENGLISH VOCABULARY VIA COMPUTER GAMING
}

\author{
Lee Luan NG*1 \\ Rino Shafierul Azizie, RAGHBIR ${ }^{2}$ \\ ${ }^{1,2}$ Universiti Malaya, Kuala Lumpur, Malaysia \\ ${ }^{1}$ ngleeluan@um.edu.my* \\ ${ }^{2}$ rinoshafierul@gmail.com
}

Manuscript received 26 October 2020

Manuscript accepted 5 June 2021

*Corresponding author

https://doi.org/10.33736/ils.2708.2021

\begin{abstract}
Due to the COVID-19 pandemic, educators have opted for online discussions and classes in which the teaching and learning sessions occur beyond the classroom environment. As various forms of technology such as gaming can be potentially used as platforms for online teaching and learning, the study aims to investigate the use of vocabulary learning strategies (VLS) in a massively multiplayer online role-playing game (MMORPG) among Malaysian English as a second language (ESL) players. Data were obtained via a 12-hour online game-play recorded sessions of Guild Wars 2 involving four Malaysian ESL players. The participants consisted of experienced online gamers aged between 24 and 25 years. The game-play sessions were also observed to provide supporting details on how the players utilised strategies when learning English vocabulary. The outcome of the study revealed that the ESL players employed different VLS during their game-play sessions. Gu and Johnson's (1996) categorisation of VLS, which are metacognitive, cognitive, memory, and activation strategies, was subsequently modified to accommodate the MMORPG context. The results showed that the top five strategies used by the players were meaning-making, consultation, using online dictionary, word comparison, and incorporating words with real-world contexts.
\end{abstract}

Keywords: Language learning; vocabulary learning strategies; MMORPG; thematic analysis; English as Second Language 


\section{Introduction}

There is an increasing number of studies that looked into various aspects of teaching and learning which focus on classroom as well as beyond-classroom learning environment, in line with the increased use of technology in teaching and learning activities. Past studies that explored the use of digital affordances in enriching the learning experience can serve as a guide in providing educators with more options in terms of incorporating technology into their instruction. Gu (2005) states that past researchers used recall tasks and artificial memory in relation to investigating how people acquire the ability to learn new vocabulary through digital games. However, in general, studies on language learning via digital games are scarce due to small sample sizes and limited duration of game-play sessions (Peterson, 2010). It is also quite difficult for researchers to adapt or replicate past studies related to vocabulary learning through digital activities as there is a lack of studies that applied vocabulary learning strategies (VLS) framework or the categorisation of VLS in beyond classroom learning environments. Although many classroom-based studies made use of $\mathrm{Gu}$ and Johnson's (1996) Categorisation of VLS, there are not many studies on VLS usage in beyond the classroom language learning setting.

There is a need to investigate the use of VLS in online gaming because researchers have indicated that vocabulary learning processes can be vital components in aiding language learners to effectively acquire their second language through digital games (Gu, 2005; Nation, 2008). Digital games are seen as a potential medium to shift the language learning curve among English as a second language (ESL) players. This is due to the technological development in digital games that creates dynamic learning environments (Golonka et al., 2012). Therefore, it is evident that digital games, especially massively multiplayer online role-playing games (MMORPGs), can potentially serve as a platform for language learning.

According to Rama et al. (2012), several past studies have looked into the potential of MMORPGs as a tool for language acquisition. Many of these studies focused on vocabulary language learning strategies in a globally renowned pay-to-play MMORPG, World of Warcraft. In the local Malaysian context, research on how players learn English vocabulary in digital-games has not been thoroughly investigated. Most past studies have only examined the effectiveness of MMORPGs in language learning, and did not focus on how ESL players are able to incorporate VLS in digital games or MMORPGs. Thus, there is a need to ascertain how non-native English players, who aim to understand and execute game tactics in MMORPGs, apply certain VLS in order to comprehend English words that they encounter in the course of playing MMORPGs. 


\section{Research Aim and Research Questions}

The study aims to investigate the VLS used in a free-to-play massively multiplayer online role-playing game (MMORPG), Guild Wars 2 among Malaysian ESL players when they are playing and interacting with other players in the game's virtual world.

The research questions are:

1) What are the VLS used by Malaysian ESL players in a MMORPG?

2) What are the functions of the VLS employed by Malaysian ESL players in MMORPGs?

\section{Literature Review}

Many theories of language learning focus on teaching and learning environments. With the expansion of technology, researchers have started to focus on alternative mediums that involve technology in language learning. In a recent study that investigated the use of technology in English language teaching, it was found that traditional English language teaching methods were considered to be irrelevant by students in current pedagogy (Mofareh, 2019). Findings showed that $60 \%$ to $80 \%$ of students were dissatisfied with the traditional way of learning language (Mofareh, 2019). The study revealed that $75 \%$ to $95 \%$ of students who were familiar with language learning through technology achieved better results in an English test than those who were accustomed to traditional classroom language learning. Thus, it seems that technology plays a crucial role in promoting an effective language learning experience for language learners. Another example of technological integration in language learning is through digital storytelling (DST) which involves a creative process of learning language through participants' visualisation and imagination (Ming et al., 2014). The implementation of DST in Malaysia has helped ESL learners to master skills like interactive communication, interpersonal skills, personal and social responsibility, technological literacy, basic and visual literacy, as well as creative thinking. Ming et al. (2014) found that Malaysian ESL students favour the implementation of DST in language teaching and learning sessions as it enhances their language learning capabilities and the ability to do collaborative work.

Simultaneously, researchers such as Mutlu and Eröz Tuğa (2013) have stated that the use of electronic devices (i.e. computers) has eased the accessibility of information and has provided students with impactful communicative technology. The use of computer-assisted language learning (CALL) is regarded as a valuable tool in aiding educators to apply multiple learning theories into instruction strategies with the assistance of computers, as well as software programmes, and is thus, an overall significant development in language teaching and learning (Mutlu \& Eröz Tuğa, 2013). Moreover, CALL also enables researchers to further understand how ESL learners enhance their language capabilities through the use of linguistic resources found online, 
their online experiences and use of computer-mediated communication (CMC) in order to become more independent learners.

\section{Online Gaming and the Use of MMORPGs in Language Learning}

There has been a tremendous growth in the popularity of online gaming since the 1990 's and its focus has expanded to both the adolescent and young adult populations (Jack \& Muhammad, 2017). Most video games are driven by immersive storylines, tactical gaming mechanisms, as well as online CMC between gamers via the use of the English language (Jack \& Muhammad, 2017). Researchers like Jack and Muhammad (2017) focused on investigating the impact of online games towards gamers' mobile language and learning capabilities. In their research, Jack and Muhammad (2017) stated that the use of MMORPGs provided participants with the ability to communicate in realtime through their in-game characters. It also enabled them to effectively express their emotions using moving emoticons that were provided in online games. Additionally, MMORPGs also provided the gamers with access to theme-based virtual worlds where they could use real-time CMC with their peers, obtain opportunities to role-play as ingame characters, participate in co-op game-play through guild membership, and take part in immersive storyline that enhances their problem-solving skills (Jack \& Muhammad, 2017). Apart from that, Butler et al. (2014) also highlighted that CALL and computer-based assessments are capable of aiding young learners to enhance their ability to present contextualised cues via animation, audio, video, as well as other multimedia tools. Through non-verbal information and instant feedback from the computer, CALL helps in gaining an individual's attention and motivating him/her to learn language (Butler et al., 2014).

In relation to language learning via MMORPG, a study by Bytheway (2015) showed that online players use their second language while playing online games, particularly in MMORPGs in order to socialise with other online players or peers. Hence, it is possible that online games can be used as a platform for language learning. MMORPG is a real-time online game that puts players in a vast and open-world virtual environment, where the storylines and quests are written mostly in English. Furthermore, players perform quests collaboratively with one another and engage in written or spoken interactions for social and in-game talk purposes (Chatfield, 2010; Mäyrä, 2008; Yee, 2006). Other researchers (Delwiche, 2006; Squire, 2005; Steinkuehler \& Squire, 2009; Yu, 2009) have also stressed the importance of MMORPG as an engaging platform for ESL players.

Although there is an increased number of past studies that looked into the potential of MMORPGs as a language acquisition tool, not many researchhave delved into the effectiveness of online gaming in relation to the implementation of VLS by ESL learners. Hence, the current study aimed to elucidate the use of VLS by ESL players in MMORPG based on the categorisation of VLS proposed by Gu and Johnson (1996), as shown in Figure 1. 
Figure 1

Gu and Johnson's (1996) Categorisation of VLS

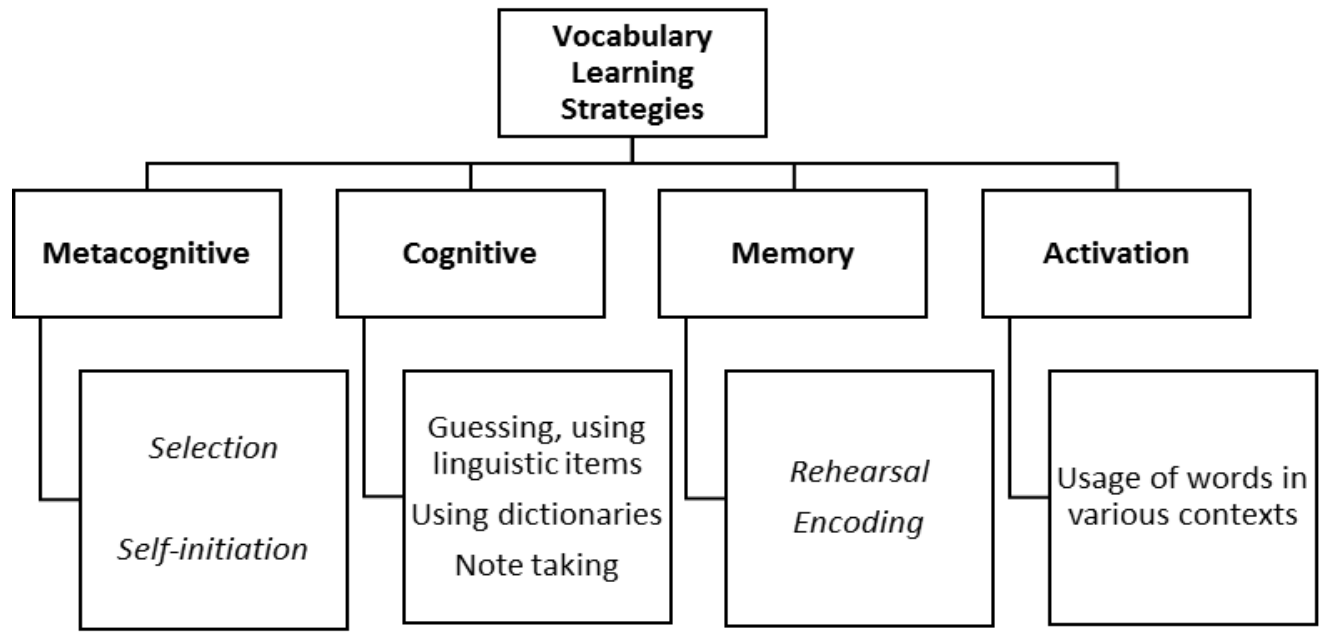

This study employed Gu and Johnson's (1996) categorisation of ESL VLS that were used to determine the relationship between VLSs and English learning outcomes among Chinese university English learners. Although the framework is effective in analysing and categorising ESL learners' use of VLS, Gu and Johnson's (1996) categorisation of VLS is not applicable in other language learning contexts other than the traditional classroom-based language learning setting. Therefore, the categorisation of VLS into metacognitive, cognitive, memory and activation by Gu and Johnson (1996) has been modified according to the exhibited behaviour during online gaming.

Prior studies have looked into the uses of different VLS by ESL learners within the online gaming platform. Also using Gu and Johnson's (1996) Categorisation of VLS, Goundar (2019) examined the different strategies that were employed by English as a Foreign Language (EFL) learners in learning new English vocabulary. Goundar (2019) found that participants employed a number of VLSs in order to acquire vocabulary and strategies that enhanced their memory-retaining skill. They also shed light on the effectiveness of VLS as a tool in describing and explaining EFL learners' language development, in addition to its capability in empowering students to choose which VLS that they require to use in order to acquire new vocabulary (Gu, 2003, as cited in Goundar, 2019).

Derakhshan and Khatir's (2015) study provided a literature review on the implementation of games as a language learning platform. With the use of vocabulary games, ESL and EFL learners' learning processes are enhanced as digital games help them to retain target words (Riahipour \& Saba, 2012, as cited in Derakhshan \& Khatir, 2015). Aghlara and Tamjid (2011) further suggested that digital games were beneficial in 
helping young English learners in vocabulary acquisition as these games were able to capture their attention.

Based on the study by Bytheway (2015), digital games are seen as valuable means of language learning due to the hundreds of millions of people who immerse themselves in digital games and communicate with each other using their second languages. According to Wenger's study (1998, as cited in Bytheway, 2015), online players act as observers and participants during game-play sessions. In doing so, they are able to pick up new English vocabulary and acquire meanings as well as definitions in order to fully understand the game. Hence, MMORPG is potentially a useful language learning platform as players are exposed to a multitude of languages due to the emphasis on communication with one another in the online gaming environment (Bytheway, 2015).

\section{Method}

Table 1 elaborates on the changes made on Gu and Johnson's (1996) categorisation of VLS to accommodate to the online gaming context.

\section{Table 1}

Changes in Gu and Johnson's (1996) Categorisation of VLS

\begin{tabular}{|c|c|c|}
\hline $\begin{array}{l}\text { Gu and } \\
\text { Johnson's } \\
\text { Vocabulary } \\
\text { Learning } \\
\text { Strategies }\end{array}$ & $\begin{array}{l}\text { Game-Related Vocabulary } \\
\text { Learning Strategies }\end{array}$ & $\begin{array}{c}\text { Explanation on Game-Related Vocabulary } \\
\text { Learning Strategies }\end{array}$ \\
\hline $\begin{array}{l}\text { Metacognitive: } \\
\text { 1. Selection } \\
\text { 2. Self- } \\
\begin{array}{l}\text { initiation }\end{array}\end{array}$ & $\begin{array}{l}\text { Metacognitive: } \\
\text { Meaning-making }\end{array}$ & $\begin{array}{l}\text { Meaning-making: ESL players initiate on } \\
\text { English vocabulary found in game-play sessions } \\
\text { by making initial meanings. }\end{array}$ \\
\hline $\begin{array}{l}\text { Cognitive: } \\
\text { 1. Guessing } \\
\text { 2. Using } \\
\\
\text { Dictionary } \\
\text { 3. } \\
\text { Note-taking }\end{array}$ & $\begin{array}{l}\text { Word Acquisition: } \\
\text { 1. Consultation } \\
\text { 2. Using Online } \\
\text { Dictionary }\end{array}$ & $\begin{array}{l}\text { Consultation: ESL players consult their friends } \\
\text { or peers to further clarify their initial meaning- } \\
\text { makings, as well as to employ other strategies } \\
\text { to get authentic definitions of the new English } \\
\text { words encountered. } \\
\text { Using Online Dictionary: ESL players spend less } \\
\text { time by referring to online dictionary using } \\
\text { Internet search engines. This strategy is more } \\
\text { effective for online gamers as it consumes less } \\
\text { time, concise, precise and easy to access from } \\
\text { their electronic devices. }\end{array}$ \\
\hline
\end{tabular}




\section{Memory: \\ 1. Rehearsal \\ 2. Encoding}

Activation:

Usage of words

in various

contexts.
Word Comparison

Activation:

Incorporating Words with

Real-World Contexts
Word Comparison: ESL players compare the English words they find during game-play sessions with other English words of similar definitions.

Incorporating Words with Real-World Contexts: ESL players associate the English words they find in game play sessions (virtual world) with real-life contexts in which they use or experience regularly.

The participants of the study consisted of four ESL players (labelled as P1, P2, P3, and P4) selected via purposive sampling method. All the participants were experienced online gamers of more than five years with a game-play duration of five to six hours a day. All the participants were 23 to 24 years old and with a background of English as their secondary language. They all scored a Band 4 in the Malaysian University English Test, which is equivalent to the intermediate level of English proficiency.

For the data collection, four game-play sessions were recorded. One of the researchers participated in the game play sessions, and also acted as an observer (labelled as P5) who noted down observational notes during the game-play sessions. The observational notes functioned as supplementary data to be triangulated with the findings. Guild Wars 2, a MMORPG genre online game was chosen as the main platform of the research as it offered an immersive storyline and a number of main quests for participants to take part in. Simultaneously, a push-to-talk software named "Discord" was used to ease the process of communication between the researchers and participants during game-play sessions as the latter were already familiar with its functions. A video recording software, Open Broadcaster Software (OBS) was also used to record the game-play sessions and to help the researchers in reviewing the video recordings and showing the specific timestamps when participants used VLS during game-play sessions.

During the four game-play sessions, all the participants were placed in the same team to enable the researchers to identify their use of different types of VLS. In order to decipher the video recordings of the game-play sessions, the software OBS was used for the specific purpose of enabling the researchers to identify how each participant had used the VLS in individual and collaborative situations. Subsequently, the participants' VLS were then categorised in accordance with Gu and Johnson's (1996) Categorisation of VLS. Figure 2 demonstrates the flow of each game-play session. 


\section{Figure 2}

\section{Game-play Session Procedure}

Session 1: Grouping of the participants in Discord. Short briefing was conducted on the rules and regulations before the start of a game session. The game session lasted for 2 hours and 38 minutes.

Session 2: The participants read through descriptions and story quests to understand the game better. They continued to explore the game map. The game session lasted for 2 hours and 26 minutes.

Session 3: The session was focused on the participants' immersion in completing the story quests during gameplay sessions. The game lasted for 2 hours and 30 minutes.

Session 4: The participants actively engaged with one anot.er and even conversed about real life matters. Along the session, the participants also came across new English words or terms that only existed in video games. The duration of the game session was 2 hours

\section{Results and Findings}

Table 2 shows the VLS most frequently used by the participants during the four gameplay sessions. Based on the frequency of VLS used by the participants, it can be seen that the different strategies employed in this study had aided the ESL players in acquiring new vocabulary through their own means. In line with that, the identified VLS will be elaborated based on the researchers' observational notes of each game-play session.

\section{Table 2}

Summary of the Five Most Frequently Used VLS in MMORPG

\begin{tabular}{lccccc}
\hline \multirow{2}{*}{$\begin{array}{c}\text { Game-Related Vocabulary Learning } \\
\text { Strategies }\end{array}$} & \multicolumn{5}{c}{ Frequency of Game-Related VLS Used } \\
\cline { 2 - 6 } & $\begin{array}{c}\mathbf{1}^{\text {st }} \\
\text { Session }\end{array}$ & $\begin{array}{c}\mathbf{2}^{\text {nd }} \\
\text { Session }\end{array}$ & $\begin{array}{c}\mathbf{3}^{\text {rd }} \\
\text { Session }\end{array}$ & $\begin{array}{c}\mathbf{4}^{\text {th }} \\
\text { Session }\end{array}$ & Total \\
\hline $\begin{array}{l}\text { Consultation } \\
\text { Incorporating Words with Real-World }\end{array}$ & 1 & 2 & 1 & 5 & $\mathbf{1 2}$ \\
Contexts & & 2 & - & 3 & $\mathbf{6}$ \\
Using Online Dictionary & 1 & 2 & - & 2 & $\mathbf{5}$ \\
Word Comparison & - & 1 & - & 3 & $\mathbf{4}$ \\
Meaning-Making & 1 & 1 & - & 2 & $\mathbf{4}$ \\
\hline
\end{tabular}


Based on findings from Gu and Johnson's study (1996), it has been established that ESL learners generally utilise VLS to understand newly identified English words through online games. Similarly, the findings in the current study have also shown that the online gaming environment assisted these ESL learners in acquiring new English words or vocabulary. Thus, the rest of this section will elaborate on the five most frequently used VLS by the ESL players during the game-play sessions.

\section{Consultation}

The next vocabulary learning strategy focuses on the participants seeking consultation from the researcher pertaining to the new vocabulary that they encountered in the MMORPG game. With the involvement of one of the researchers in the game-play sessions, the participants seemed to be more actively engaged in vocabulary language activities. The participants considered one of the researchers as a "walking library", in which they would consult the researcher to confirm or further fortify their initial meaning-making of the new English vocabulary encountered during their game-play session (Table 3).

\section{Table 3}

Consultation Strategy

\begin{tabular}{|c|c|c|}
\hline VLS & Instances of VLS & Observational Notes \\
\hline \multirow[t]{2}{*}{ Consultation } & $\begin{array}{l}\text { Example 1: } \\
\text { P4 (2:27:01): } * * * *(P 5) \text {, is there a word } \\
\text { such as completionist? } \\
\text { P5 (2:27:21): I think it's more of a } \\
\text { perfectionist. I don't think it's a formal } \\
\text { word. }\end{array}$ & $\begin{array}{l}\text { 1. It seems that participants } \\
\text { were more motivated to use } \\
\text { consultation strategy during } \\
\text { game-play sessions because } \\
\text { the researcher (P5) has an } \\
\text { academic background in } \\
\text { English linguistics. }\end{array}$ \\
\hline & $\begin{array}{l}\text { P4 (2:27:31): Because there's a quest } \\
\text { called Completionist. I don't know } \\
\text { whether this is a valid word or not. } \\
\text { Example 2: } \\
\text { P4 (0:00:13): **** (P5), what is the } \\
\text { meaning of tarnish? Because I see one in } \\
\text { the map and still haven't had a clue and } \\
\text { that's why I ask you. }\end{array}$ & $\begin{array}{l}\text { 2. Participants would usually } \\
\text { consult the researcher when } \\
\text { they found new English } \\
\text { words that are not widely } \\
\text { used in the real-world } \\
\text { context or that are created } \\
\text { specifically for online gaming. }\end{array}$ \\
\hline
\end{tabular}

The consultation strategy was employed by the participants to further clarify their initial understanding of new words created through the meaning-making strategy. The consultation with the researcher enables these participants to obtain more accurate definitions of the new words. Furthermore, it has also been observed that the 
consultation strategy was frequently employed when the participants were unable to fully understand the meanings of the English words.

To exemplify this case, P4 in Example 1 sought consultation from the researcher regarding the words "completionist" and "tarnish". By employing this strategy, P4 was able to understand the meaning of the two new words when they were explained by the researcher. In addition, the researchers also provided examples as part of the explanation to help participants understand these words.

Nosidlak (2013) emphasised the use of the strategy involving asking others in which one would obtain the meaning of a new word by inquiring others (i.e. students, native speakers, and teachers). According to Hatch and Brown (1995, as cited in Nosidlak, 2013), the depth of meaning-making can vary across different sources, and that learners are required to adhere to the different ways of acquiring meaning in order to fully comprehend the actual definitions of words. A similar finding is noted in the current study where the participants consulted the researchers as the main source of acquiring information. Other than the utilisation of the consultation strategy, both participants and researchers adopted another strategy to obtain meanings of new words that included consulting online dictionaries.

\section{Incorporating words with real-world contexts}

The final VLS found in the study is incorporating words with real-world contexts. Based on Gu and Johnson's (1996) activation category, ESL learners would use new words in various contexts in order to obtain a deeper comprehension. However, in the context of the current study, the ESL players had linked the English words that they came across during their game-play sessions with English words found in real-world situations. Hence, the ESL learners were able to understand word definitions found in digital games through real-world circumstances (that is, objects, surroundings, and so on).

Table 4

Incorporating Words with Real-world Contexts

\begin{tabular}{lll}
\hline VLS & \multicolumn{1}{c}{ Instances of VLS } & \multicolumn{1}{c}{ Observational Notes } \\
\hline & P5 (1:08:53): I don't think it has a root & Participants were able to \\
word. The word itself is oscillator. & $\begin{array}{l}\text { make sense of complex } \\
\text { English words when they }\end{array}$ \\
$\begin{array}{l}\text { Incorporating } \\
\text { Words with }\end{array}$ & P3 (1:08:58): The nearest word is tried to use these words \\
$\begin{array}{l}\text { Real-World } \\
\text { Contexts }\end{array}$ & $\begin{array}{l}\text { oscillation, where you change the fan from in real-world contexts. } \\
\text { being static to movement (turning around } \\
\text { in 180 degrees). }\end{array}$ \\
\hline
\end{tabular}

Based on Table 4, it can be seen that P3 was able to relate the word "oscillator" with a real-world object (a fan) in order to obtain a deeper understanding of the complex word. In Example 1, P3 stated that an "oscillator" might have a close resemblance to the word "oscillation" (moving the fan from static to motion). In this 
case, P3 had the general idea that an oscillator is associated with an electronic device that produces the movement of swinging back and forth in a regular rhythm (similar to an auger). Hence, the participants were able to comprehend the complex word "oscillator" by relating it to a real-world object.

Derakhshan and Khatir (2015) pointed out the positive implications of using games on English vocabulary learning in ESL and EFL contexts. In their study, Derakhshan and Khatir (2015) explained the benefits of using educational games for English vocabulary teaching and learning sessions, and highlighted that these vocabulary-promoting games have helped to bring the real-world context into classroom teaching and learning sessions. As a result, students' English language proficiencies were enhanced as they were able to use the language in a flexible and communicative way. In view of the use of MMORPG as a vocabulary language learning platform, the participants of this study were able to relate complex words with the objects or matters from real-world contexts. Hence, this has enabled them to fully comprehend the new English words found in the game, as well as recognise the appropriate contexts in which the complex English vocabulary can be used.

\section{Using online dictionary}

In accordance with the study by Gu and Johnson (1996), the cognitive aspect of VLS involves ESL learners using dictionaries when searching for the definition of a new vocabulary. However, in the context of online gaming, referring to a physical dictionary was difficult for the ESL players as they were highly immersed in the game that required their full attention at all times. Hence, the researchers have adapted the strategy mentioned in Gu and Johnson's (1996) framework to using online dictionary to accommodate the online gaming context. As facilitators and observers of the study, the researchers were able to provide explanation, to the participants, on the new English words that they encountered in all four game-play sessions. These participants also had the flexibility to access online search engines (Google) in order to further clarify the new English vocabulary encountered. For ESL learners, understanding new English words can be difficult as their thought processes are based on their native language. Hence, most bilingual ESL learners tend to utilise a dictionary more than monolinguals (Tahriri \& Ariyan, 2015). A similar situation is observed in this study, whereby these bilingual ESL participants frequently utilised online dictionaries during the game-play sessions in their effort to understand the meaning of new vocabulary. The Electronic Dictionary (ED), as proposed by Rezaei and Davoudi (2016) provides an accurate definition of words within a short period of time. Based on what was observed during the sessions, these ESL players had benefited from using online dictionaries during their game-play sessions due to its easy accessibility and accurate results. 
Table 5

Using Online Dictionary Strategy

\begin{tabular}{|c|c|c|}
\hline VLS & Instances of VLS & Observational Notes \\
\hline $\begin{array}{l}\text { Using } \\
\text { Online } \\
\text { Dictionary }\end{array}$ & $\begin{array}{l}\text { Example 1: } \\
\text { P2 (1:07:16): Oscillator? What's an } \\
\text { oscillator? Dredge Oscillator... (The } \\
\text { participant refers to the name of a monster } \\
\text { in Guild Wars 2) } \\
\text { P5 (1:07:45): I can Google it for you guys } \\
\text { because I rarely use this term. It's defined as } \\
\text { a mechanical device used to dig tunnels. It's } \\
\text { like a drill (auger). } \\
\text { Example 2: } \\
\text { P4 (2:27:31): Because there's a quest called } \\
\text { Completionist. I don't know whether this is } \\
\text { a valid word or not. } \\
\text { P5 (2:27:44): It's actually a noun in a video } \\
\text { game. The word is only created for online } \\
\text { gaming purposes. It is defined as a player } \\
\text { that attempts to complete every challenge } \\
\text { in order to get the achievements. For } \\
\text { example, when you play DoTA, you get } \\
\text { achievements, right? }\end{array}$ & $\begin{array}{l}\text { 2. Due to the nature of the } \\
\text { Electronic Dictionary (ED), it } \\
\text { was easier for the } \\
\text { researcher to aid } \\
\text { participants in terms of } \\
\text { providing word definitions, } \\
\text { as the online dictionary was } \\
\text { easy to access and has } \\
\text { provided quick results. }\end{array}$ \\
\hline
\end{tabular}

As shown in Table 5, the participants approached the researchers to clarify the definitions of complex English words. The researchers were also relying on online dictionaries to provide accurate meanings of these new words. Considering that the online gaming environment restricts online gamers from pausing the game (real-time game mechanics), the researchers found that using an online dictionary was a more convenient method to learn English when one is in a gaming context. The ED is a powerful tool that can be accessed via the Google search engine, hence, it serves as an effective linguistic tool that can be used during the game-play sessions. Furthermore, since Guild Wars 2 is playable on a personal computer, switching between the online game and the Internet to retrieve the accurate definitions of words the participants encountered during gaming can be done swiftly.

As opposed to Gu and Johnson's (1996) traditional way of using Paper Dictionaries, the current research focuses more on the use of ED due to its compatibility with the fast-paced online gaming environment. With reference to the timestamps of both Examples 1 and 2 in Table 5, the researchers were able to allocate less than a minute to find out the definitions for complex English words, for example, "oscillator" and "completionist". This exemplifies the ease of using an online dictionary to provide 
learners with concise interpretation of English words which could result in the improvement of their vocabulary language acquisition.

Rezaei and Davoudi (2016) highlighted the idea of using online dictionaries to reinforce ESL learners' ability to acquire new vocabulary. The participants in their study were reluctant to flip through Paper Dictionaries to search for word definitions as it consumed an excessive amount of time and adversely impacted the flow of reading written texts. Similarly, having participants flipping through Paper Dictionaries while in gaming sessions is deemed time-consuming. In addition, this act could disrupt their immersion in the game-play sessions. However, by using online dictionaries, the participants of this study were able to acquire new English vocabulary faster and with better understanding of definitions of words.

\section{Word comparison}

As one of VLS, the aim of using the word comparison strategy is so that ESL learners can understand the new words based on other words that they are already familiar with. Based on this study, by comparing or suggesting complex words found in the game-play sessions with other simpler terms, the researchers were able to aid the participants' vocabulary learning process.

Table 6

Word Comparison Strategy

\begin{tabular}{|c|c|c|}
\hline VLS & Instances of VLS & Observational Notes \\
\hline $\begin{array}{c}\text { Word } \\
\text { Comparison }\end{array}$ & $\begin{array}{l}\text { Example 1: } \\
\text { P4 (0:01:51): So, what's the difference } \\
\text { between tarnish and melt, if you say the } \\
\text { example like the metal on the car just now? } \\
\text { Example 2: } \\
\text { P5 (0:02:00): Tarnish means that - for } \\
\text { example you take a red car. Then the paint } \\
\text { comes off right? So, that is what we call } \\
\text { tarnish. The surface of the car has been } \\
\text { tarnished. However, melting is the state of } \\
\text { the metal from the body of the car. The } \\
\text { structure melts. }\end{array}$ & $\begin{array}{l}\text { Participants understood the } \\
\text { complexity of English words } \\
\text { found in the game-play } \\
\text { sessions when the } \\
\text { researcher compared these } \\
\text { words with simple English } \\
\text { vocabulary. }\end{array}$ \\
\hline
\end{tabular}

Table 6 shows the researchers using the word comparison strategy to aid the participants in making sense of the complex words that they encountered during the game-play sessions. In Example 1, the researchers were trying to define the complex word "tarnish" by using a simpler term "melt". Although the two words are slightly different in their definitions, the researchers were able to help P4 understand better due to the similar properties carried by the two words (both "tarnish" and "melt" are inked to corroding properties). 
A study on the effects of synonyms in second-language vocabulary learning among ESL learners by Webb (2007) demonstrated that synonyms have the potential to facilitate vocabulary learning among ESL learners. The participants were able to gain vocabulary knowledge through repeated exposures to new English words (Day et al., 1991, as cited in Webb, 2007). Similar to synonyms, word comparison helps ESL learners to grasp English vocabulary faster as they are exposed to simpler definitions as opposed to the complex meanings when they first encounter these words. In short, word comparison is effective because it provides ESL learners with simple definitions when explaining complex English words or terminologies.

\section{Meaning-making}

The first VLS is meaning-making. It seemed that the participants' awareness and comprehension of thought processes are the two crucial factors involved in the selection of new vocabulary during game-play sessions.

Table 7

Instances of Meaning-making Strategy among Players

\begin{tabular}{|c|c|c|}
\hline VLS & Instances of VLS & Observational Notes \\
\hline \multirow{6}{*}{$\begin{array}{l}\text { Meaning- } \\
\text { Making }\end{array}$} & Example 1: & 1. The participants employed \\
\hline & $\begin{array}{l}\text { P1 (1:12:48): So, it's actually } \\
\text { another term for engrave, is it? }\end{array}$ & $\begin{array}{l}\text { meaning-making strategy in } \\
\text { order to make sense of what } \\
\text { the English words mean. }\end{array}$ \\
\hline & Example 2: & \multirow{4}{*}{$\begin{array}{l}\text { 2. Participants correlated the } \\
\text { new English words with other } \\
\text { known English vocabulary or } \\
\text { things that contribute to the } \\
\text { creation of initial definitions of } \\
\text { the new words. }\end{array}$} \\
\hline & $\begin{array}{l}\text { P2 (1:07:16): Oscillator? What's } \\
\text { an oscillator? Dredge Oscillator... }\end{array}$ & \\
\hline & $\begin{array}{l}\text { (The participant refers to the } \\
\text { name of a monster in Guild Wars } \\
\text { 2) }\end{array}$ & \\
\hline & $\begin{array}{l}\text { P1 (1:08:32): Is it the same like } \\
\text { something that goes back and } \\
\text { forth - (The participant is referring } \\
\text { to an auger) }\end{array}$ & \\
\hline
\end{tabular}

Most participants employed the meaning-making strategy in order to comprehend initial meanings of the new English words that they encountered throughout the game-play sessions. This strategy was viewed as crucial by these Malaysian ESL learners as they were able to employ other VLS in order to strengthen their initial understanding. In addition, the participants' background knowledge also played an essential part in the creation of early understanding derived from their thought processes. With the help of their schema, the participants were able to deduce 
new English words by correlating them with other English vocabulary or things of similar attributes.

In reference to Table 7, the participants employed the meaning-making strategy when they first encountered the new words during the game-play sessions. The purpose of employing this strategy was for the participants to comprehend the initial meanings of the new English words. The researchers believed that these participants were also trying to relate the words with other known English words and relating these words with things that would contribute to the initial definitions created. Referring to Example 1, P1 attempted to make sense of the word "imbue" by relating it with another known English word "engrave". It can be assumed that P1 had employed the meaning-making strategy to further enhance her comprehension of this new word by relating the term to another word with a similar meaning, such as "engrave". Meaning-making is considered a vocabulary learning strategy that had helped the participants to take the first step in acquiring new English vocabulary.

A recent study by Goundar (2019) found that metacognitive learning strategies such as selective attention and self-initiation were employed by ESL learners to prioritise words that appeared more important for them to learn and make initial meanings out. A similar case can be seen among the participants of this study as they created new definitions for the new English vocabulary that were identified during the game-play sessions. These participants used the meaning-making strategy to initiate the vocabulary learning process. The reason behind the use of this strategy was to help the ESL learners to understand any information in text format that were visible and related to their understanding of the storyline in Guild Wars 2.

\section{Conclusion}

The study has illustrated the role of online gaming in motivating ESL learners to learn English words in an immersive digital environment. In addition, the findings also show that the immersive and multidimensional attributes of online games can enhance the learning capabilities of ESL learners as this learning platform is learner-centred, as opposed to the teacher-centred approach used in a conventional classroom setting. Amidst the present global COVID-19 pandemic, the findings of the current study have demonstrated how online games can enhance the English language learning experience of learning beyond the classroom context. However, the limitation of this study is that it only involves four participants as study samples. The selection of these participants may be deemed insufficient in proving that online games are effective in helping ESL learners to incorporate VLS to acquire new English vocabulary. Therefore, future studies should involve a bigger sample size. Additionally, the current study does not investigate the effectiveness of other online gaming genres other than MMORPG in looking into how ESL learners implement different VLS to learn a language. Therefore, future researchers should consider conducting studies on the use of VLS by other ESL groups of learners and focusing on the effectiveness of VLS across other online gaming platforms. 


\section{References}

Aghlara, L., \& Tamjid, N. H. (2011). The effect of digital games on Iranian children's vocabulary retention in foreign language acquisition. Procedia - Social and Behavioral Sciences, 29, 552-560. https://doi.org/10.1016/j.sbspro.2011.11.275

Butler, Y., G., Someya, Y., \& Fukuhara, E. (2014). Online games for young learners' foreign language learning. ELT Journal, 68(3), 265-275. https://doi.org/10.1093/elt/ccu008

Bytheway, J. (2015). A taxonomy of vocabulary learning strategies used in massively multiplayer online role-playing games. CALICO Journal, 32(3), 508-527. https://doi.org/10.1558/cj.v32i3.26787

Chatfield, T. (2010). My TED talk: 7 ways games reward the brain. Tom Chatfield. https://www.tomchatfield.net/portfolio/tom_chatfield_7_ways_games_rewar d_the_brain/

Delwiche, A. (2006). Massively multiplayer online games (MMOs) in the new media classroom. Educational Technology \& Society, 9(3), 160-172. https://www.jstor.org/stable/jeductechsoci.9.3.160

Derakhshan, A., \& Khatir, E., D. (2015). The effects of using games on English vocabulary learning. Journal of Applied Linguistics and Language Research, 2(3), 39-47. http://www.jallr.com/index.php/JALLR/article/view/40.69

Golonka, E. M., Bowles, A. R., Frank, V. M., Richardson, D. L., \& Freynik, S. (2012). Technologies for foreign language learning: A review of technology types and their effectiveness. Computer Assisted Language Learning, 27(1), 70-105. https://doi.org/10.1080/09588221.2012.700315

Goundar, P. R. (2019). Vocabulary learning strategies (VLSs) employed by learners of English as a foreign language (EFL). English Language Teaching, 12(5), 177-189. https://doi.org/10.5539/elt.v12n5p177

Gu, P. Y. (2005). Vocabulary learning strategies in the Chinese EFL context. Marshall Cavendish Academic.

Gu, P. Y., \& Johnson, R. K. (1996). Vocabulary learning strategies and language learning outcomes. Language Learning, 46, 643-679. https://doi.org/10.1111/j.14671770.1996.tb01355.x

Jack, C. S., \& Muhammad, M. M. (2017). Online games: The impact on gamers' mobile language and language learning. Science International (SI), 29(1), 165-168. http://www.sci-int.com/pdf/636297108114854359.pdf

Mäyrä, F. (2008). An introduction to game studies: Games in culture. SAGE Publications Ltd. http://dx.doi.org/10.4135/9781446214572

Ming, T. S., Sim, L. Y., Mahmud, N., Kee, L. L., Zabidi, N. A., \& Ismail, K. (2014). Enhancing 21st century learning skills via digital storytelling: Voices of Malaysian teachers and undergraduates. Procedia - Social and Behavioral Sciences, 118, 489-494. https://doi.org/10.1016/j.sbspro.2014.02.067 
Mofareh, A. A. (2019). The use of technology in English language teaching. Frontiers in Education Technology, 2(3), 168-180. http://ijreeonline.com/article-1-120en.html

Mutlu, A., \& Eröz-Tuğa, B. (2013). The role of computer-assisted language learning (CALL) in promoting learner autonomy. Egitim Arastirmalari-Eurasian Journal of Educational Research, 107-122. https://files.eric.ed.gov/fulltext/EJ1059921.pdf

Nation, P. (2008). Teaching vocabulary: Strategies and techniques. Heinle.

Nosidlak, K. M. (2013). Vocabulary learning strategies of the advanced students. Journal of Language Teaching and Research, 4(4), 655-661. https://pdfs.semanticscholar.org/9f22/98008ee3b5838f68ec20c68ced8471a8b 5e8.pdf

Peterson, M. (2010). Computerized games and simulations in computer-assisted language learning: A meta-analysis of research. Simulation \& Gaming, 41(1), 72-93. https://doi.org/10.1177\%2F1046878109355684

Rama, P. S., Black, R. W., van Es, E., \& Warschauer, M. (2012). Affordances for second language learning in World of Warcraft. ReCALL, 24, 322-338. https://doi.org/10.1017/S0958344012000171

Rezaei, M., \& Davoudi, M. (2016). The influence of electronic dictionaries on vocabulary knowledge extension. Journal of Education and Learning, 5(3), 139-148. https://doi.org/10.5539/jel.v5n3p139

Squire, K. D. (2005). Game-based learning: Present and future state of the field. Masie Center e-Learning Consortium.

Steinkuehler, C., \& Squire, K. (2009). Virtual worlds and learning. On the Horizon, 17(1), 8-11. https://doi.org/10.1108/10748120910936108

Tahriri, A., \& Ariyan, Z. (2015). Use of monolingual, bilingual, and bilingualised dictionaries and EFL learners' vocabulary learning strategies: A case study. Issues in Language Studies, 4(1), 75-89. https://doi.org/10.33736/ils.1647.2015

Webb, S. (2007). The effects of synonymy on second-language vocabulary learning. Reading in a Foreign Language, 19(2), 120-136. https://files.eric.ed.gov/fulltext/EJ777733.pdf

Yee, N. (2006). The demographics, motivations, and derived experiences of users of massively multi-user online graphical environments. Presence: Teleoperators and Virtual Environments, 15(3), 309-329. https://doi.org/10.1162/pres.15.3.309

$\mathrm{Yu}, \mathrm{T}$. W. (2009). Learning in the virtual world: The pedagogical potentials of massively multiplayer online role playing games. International Education Studies, 2(1), 3238. https://doi.org/10.5539/IES.V2N1P32 